\title{
ARTICLE
}

\section{Clear-water scour at submerged pile groups}

\author{
Alvaro Galan ${ }^{\mathrm{a}}$, Gonzalo Simarro ${ }^{\mathrm{b}}$, Cristina Fael $^{\mathrm{c}}$ and Antonio H. Cardoso ${ }^{\mathrm{d}}$ \\ a Departamento de Ingeniería Civil y de la Edificación, Universidad de Castilla-La Mancha, Ciudad Real, Spain; \\ ${ }^{b}$ Institut de Ciències del Mar (ICM-CSIC), Barcelona, Spain; ${ }^{c} \mathrm{C}-\mathrm{MADE}$, Universidade da Beira Interior, Covilhã, \\ Portugal; ${ }^{\mathrm{d} C E R I S}$, Instituto Superior Técnico, Universidade de Lisboa, Lisboa, Portugal
}

\begin{abstract}
ARTICLE HISTORY
Compiled February 28, 2018

ABSTRACT

Accurate estimates of the scour depth around submerged pile groups is important in river engineering for a number of reasons, however, the literature on this issue is scarce. This study introduced an experimental campaign of 48 long-duration clear water experiments at submerged and skewed pile groups composed of cylindrical elements under steady flow. The effects of the skew-angle, submergence ratio and pile group configuration on the equilibrium scour depth was investigated. The experimental scour depths were compared with results from the HEC-18 empirical method and a modification of it to take into account a wide range of submergence ratios was proposed. Further, a new formulation to estimate the equilibrium scour depth at submerged pile groups was introduced with good agreement for the tests under consideration. Some considerations about the most employed characteristic lengths used to normalize the equilibrium scour depth were made.
\end{abstract}

\section{KEYWORDS}

Bridges; erosion processes; habitat hydraulics; laboratory studies; river training structures

\section{Introduction}

Pile groups are frequently used to support the pile-cap of complex piers in river bridges. They are also used in the open sea to support sub-sea structures such as caissons, gravity anchors or platform foundations in the offshore oil and gas industry. Pile groups are said to be submerged when the flow depth is greater than the height of the piles (Dey et al., 2008), as shown in Fig. 1.

Understanding and predicting scour around submerged pile groups is of interest for, at least, four different reasons. First, pile groups may be submerged in flood events during the construction phase of complex bridge piers. Second, apart from the method presented by Amini and Thamer (2016), most 


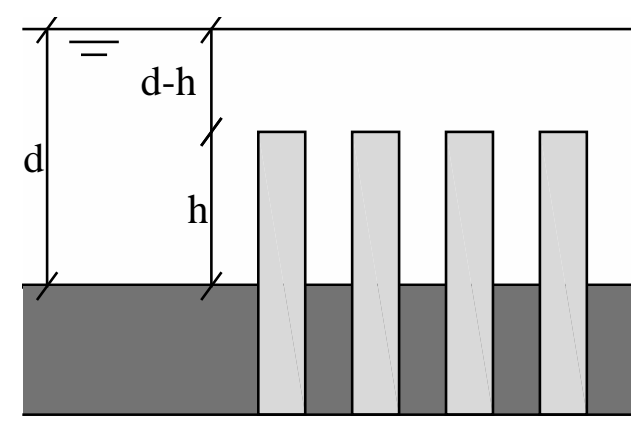

Figure 1. Pile group submergence definition.

methods to estimate local scour in complex piers assume the superposition of partial scour due to different components of the pier: the pier-stem, the pile-cap and, also, the pile group (Richardson and Davis, 2001; Sheppard and Glasser, 2004; Sheppard and Renna, 2010, e.g.). Some other methods can be found in the literature which individually calculate the locar scour depth caused by each of those elements (for instance, Amini et al. (2012) for the pile group or Amini et al. (2011) for the pile cap), although, according to Amini et al. (2014), the use of superposition methods to estimate total scour depth at complex piers as the sum of the scour depths due to each element, can lead to inaccurate predictions. Third, different types of submerged structures have been used as countermeasures against local scour at other structures (Razmi et al. 2014), and also to generate scour holes to enhance river habitats (Shamloo et al., 2001). Finally, the values of maximum scour depth at submerged obstacles may be useful in studies for paleo-flow estimations (Euler and Herget, 2011). While there is much literature on the study of scour at emergent (not submerged) piles and pile groups (Azamathulla et al., 2013, Breusers et al. 1977; Hosseini and Amini, 2015, Melville, 1997, among many others), to the authors knowledge, there are only a few experiments for the submerged case.

At emergent isolated piles, the flow field is characterized by a bow wave, a down-flow, the horseshoe vortex and wake vortices. At (emergent) pile groups, the flow features generated at the individual piles, being essentially the same as for the single pile case, interact with one another creating a complex 3D flow. The intensity and implications of these interactions depend mostly on the spacing between piles forming the group and the alignment or skew-angle of the group (Chreties et al., 2013, Lanca et al. 2013, among others).

a At submerged obstacles the three dimensional nature of the flow becomes more prominent (Sarkar and Ratha, 2014). At isolated (submerged) piles, the bow wave, which also exists, tends to vanish; a trailing vortex develops at the top of the pile (Bauri and Sarkar, 2016); the size and strength of the horseshoe vortex tend to diminish and the down-flow becomes feeble as the submergence increases (the submergence, $S_{r}$, is herein defined as $S_{r} \equiv(d-h) / d$ with $d=$ flow depth and $h=$ height of the obstacle above the undisturbed bed, see Fig. 11. Hence, the scour depth diminishes as the submergence increases (Dey et al. 2008). These same tendencies may be expected to be manifested at submerged pile groups. Dey et al. (2008), Zhao et al. (2010) and Euler and Herget (2011) are among the few experimen- 
tal works that studied scouring at isolated submerged piles, concluded that the maximum scour depth decreases with increasing submergence. All three works analysed only short-duration experiments (few hours), so that equilibrium conditions were not reached. Euler and Herget (2011) has accounted for the effect of the sediment coarseness ratio, $D_{p} / D_{50}\left(D_{p}=\right.$ pile diameter; $D_{50}=$ median sand grain size $)$, and sand gradation, $\sigma_{D} \equiv \sqrt{D_{84} / D_{16}}$, and introduced the obstacle-Reynolds number $\left(\operatorname{Re} \equiv U D_{p} / \nu\right.$, $U=$ mean approaching velocity and $\nu=$ kinematic viscosity of water) as one of the key parameters in determining the equilibrium scour depth at submerged cylinders. The study by Zhao et al. (2010) covered weak live-bed flow conditions on ripple-forming sand, where ripples may have masked maxima scour depths. Studies on scouring at submerged pile groups are also scarce. They include those by Salim and Jones (1996), Richardson and Davis (2001), Sheppard and Renna (2010) and Amini et al. (2012). The goal of the studies by Richardson and Davis (2001) and Sheppard and Renna (2010) was to obtain the total scour at complex piers (pier-stem, pile-cap and pile group), and the expressions for the submerged pile group scour are obtained indirectly from the total scour. Salim and Jones (1996) and Amini et al. (2012) report experiments on clear-water scour for different spacing, layout and submergence ratios. Leaving aside the short duration of the experiments in both studies (4 and 8 hours respectively), none of them included the effect of the skew-angle (angle between the mean flow and the longitudinal axis of the group).

Given the above background, the present study analyses the effect of submergence and group skewangle on the equilibrium scour depth of submerged groups made up of cylindrical piles when neither pile cap nor pier stem are included. Two main distinctive features of this study are: 1) the long duration of the experiments, 9 days in average, which allows to properly estimate the equilibrium scour depth, and 2) the analysis of the influence of both the skew-angle and submergence, using four different skew-angles and six submergence ratios.

\section{Dimensional Analysis Framework and Preliminary Definitions}

According to Lanca et al. (2013) the equilibrium scour depth at emergent pile groups composed of cylindrical piles (i.e., the maximum of the equilibrium scour depth at all piles), $d_{E g e}$, is given by

$$
\frac{d_{E g e}}{D_{p}}=\phi\left(\frac{S}{D_{p}}, \alpha, m, n\right)
$$

where $\phi$ stands for "function of"; $S=$ pile spacing as shown in Fig. 2 , $\alpha=$ pile group skew-angle; $m=$ number of rows in the group; $n=$ number of columns in the group; and $S / D_{p}=$ normalized pile spacing.

Above, the subscripts " $E$ ", " $g$ " and " $e$ " stand for "Emergent", "group" and "equilibrium" respectively. Hereafter, other subscripts will be used, e.g., " $S$ " will stand for "Submerged" and " 0 " for the 


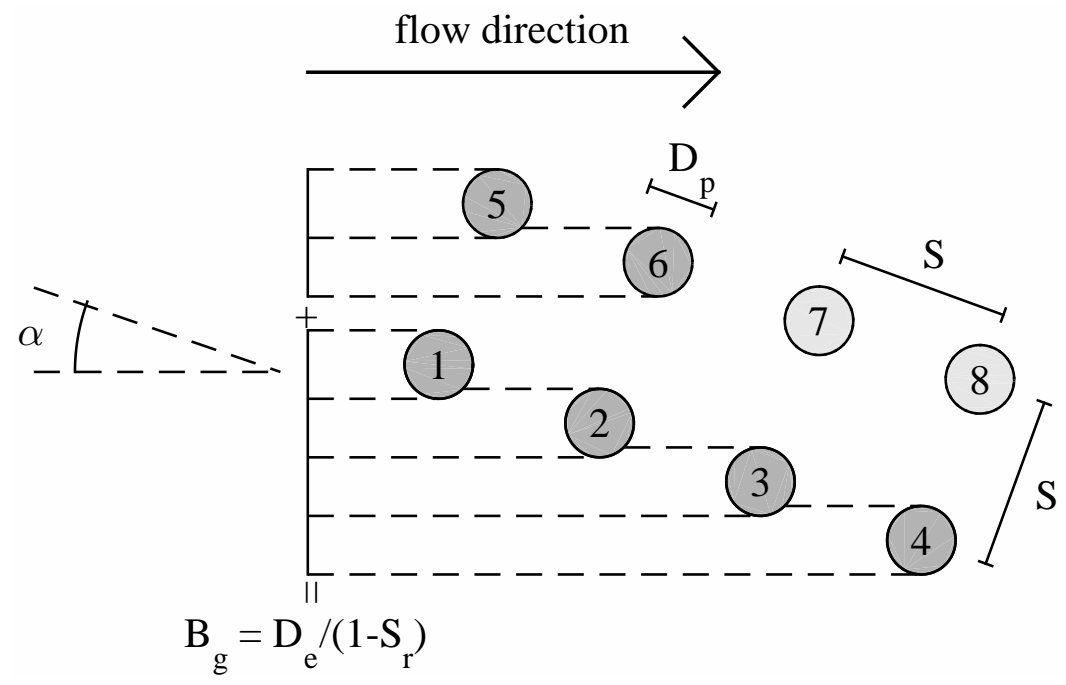

Figure 2. Characteristic variables of a pile group. For this figure values of $S / D_{p}=2.5, \alpha=20^{\circ}, m=4$ and $n=2$ have been used.

cases where $\alpha=0$. Equation (1) is valid if the following conditions apply:

(1) the pile group is in a wide rectangular channel, i.e., the effects of the wall and the cross-sectional shape are negligible and the approach velocity field is $2 \mathrm{D}$ at the central section of the channel, which implies $B / d>5(B=$ channel width);

(2) the channel bed material is composed of uniform $\left(\sigma_{D}<1.5\right)$ non-ripple forming sand $\left(D_{50}>\right.$ $0.60 \mathrm{~mm})$;

(3) the ratio $\rho_{s} / \rho$ is constant ( $\rho_{s}=$ sediment density, $\rho=$ water density);

(4) the approach flow is fully developed and uniform, and viscous effects are negligible;

(5) contraction scour is negligible, which according to Ballio et al. (2009) is guaranteed if the sum of the non-overlapping elemental pile widths projected on a plane normal to the approach flow direction, $B_{g}$, (Fig. 2), is less than $10 \%$ of the flume width;

(6) the flow depth is large enough to neglect flow shallowness effects on scour depth, i.e., d/ $D_{p} \gtrsim$ 2.5 ;

(7) the flow intensity, $U / U_{c}$ ( $U_{c}=$ average approach flow velocity for the threshold of sediment entrainment), and sediment coarseness, $D_{p} / D_{50}$, are constant.

The above conditions are very common in local scour experiments and, as it will be shown in the following section, the experiments in the present work satisfy the same conditions. Further, the flow intensity and sediment coarseness factors were chosen so as to practically maximize the scour depth $\left(U / U_{c} \approx 1 ; D_{p} / D_{50} \lesssim 100\right)$.

In the experimental campaign, pile spacing was set constat at $S / D_{p}=2.5$ (a usual value in practice) and the number of rows was set constant at $m=4$, while the submergence ratio, $S_{r}$, the skew-angle, $\alpha$, 
and the number of columns, $n$, were varied. Hence, Equation (1) may be adapted to read

$$
\frac{d_{S g e}}{D_{p}}=\phi\left(S_{r}, \alpha, n\right) .
$$

In the above expression (2), $D_{p}$ appears as the normalizing length for the equilibrium scour depth. However, in pile group scour, other lengths have been proposed. For example, $n D_{p}$ or $B_{g}$ defined in Fig. 2, which introduces the skew-angle $\alpha$ (note that $n D_{p}=B_{g}$ for $\alpha=0$ ). The "equivalent" diameter

$$
D_{e} \equiv B_{g}\left(1-S_{r}\right),
$$

further introduces the submergence in contrast to $B_{g}$ (Coleman, 2005).

It can be shown that Equation (2) is equivalent to

$$
\frac{d_{S g e}}{n D_{p}}=\phi\left(S_{r}, \alpha, n\right), \quad \frac{d_{S g e}}{B_{g}}=\phi\left(S_{r}, \alpha, n\right), \quad \text { or } \quad \frac{d_{S g e}}{D_{e}}=\phi\left(S_{r}, \alpha, n\right) .
$$

Equation (4) may be further replaced by

$$
\frac{d_{\text {Sge }}}{d_{n D_{p}}}=\phi\left(S_{r}, \alpha, n\right), \quad \frac{d_{\text {Sge }}}{d_{B_{g}}}=\phi\left(S_{r}, \alpha, n\right), \quad \text { or } \quad \frac{d_{\text {Sge }}}{d_{D_{e}}}=\phi\left(S_{r}, \alpha, n\right),
$$

with $d_{x}=$ equilibrium scour depth associated to an isolated emergent pile of diameter $x$ under the same flow conditions. For instance, the expression proposed by Amini et al. (2012), initially derived to estimate local scour at submerged and emergent pile groups aligned with the flow $(\alpha=0)$ with different pile spacing ( $\left.1 \leq S / D_{p} \leq 6.4\right)$ and different values of $m$ and $n$, can be simplified by assuming, as we do here, $S / D_{p}=2.5$ and $m=4$, to read as follows

$$
\frac{d_{S g e}}{d_{n D_{p}}}=C K_{h} K_{S m n},
$$

being $K_{h}=\phi\left(S_{r}\right), K_{S m n}=\phi(n)$ and $C=0.99$ for the emergent case and $C=0.83$ for the submerged one. Note that Equation (6) and the values for the coefficient given before are only valid when $S / D_{p}, m$ and $n$ take the values employed in the present work.

The expression proposed by Richardson and Davis (2001), known as HEC-18 method, is, under the above conditions,

$$
\frac{d_{S g e}}{D_{p}}=2.2 K_{h}\left(\frac{d}{D_{p}}\right)^{0.135}\left(\frac{B_{g} K_{s p} K_{m}}{D_{p}}\right)^{0.65}\left(\frac{U}{\sqrt{g D_{p}}}\right)^{0.43},
$$

with $K_{h}=\phi\left(S_{r}\right)$, but different from the one by Amini et al. (2012), $K_{s p}=\phi\left(D_{p} / B_{g}, S / D_{p}\right)$, $K_{m}=\phi\left(m, S / D_{p}\right)$ and $g=$ gravitational acceleration. Note that the influence of $d / D_{p}$ is small in the above expression (which is consistent with the flow shallowness condition we have assumed above). 
Sheppard and Renna (2010) proposed a different equivalent pile group diameter, given by $D_{*} \equiv$ $D_{p} K_{m} K_{s p} K_{h} K_{s h}$ where, $K_{m}=\phi(m, \alpha)$ and the rest of functions $K$ are expressions involving, among others, the submergence. Once $D_{*}$ has been computed, their expression for the scour depth reads, for $U / U_{c} \sim 1$,

$$
\frac{d_{\text {Sge }}}{D_{*}}=2.5 f_{1}\left(\frac{d}{D_{*}}\right) f_{3}\left(\frac{D_{*}}{D_{50}}\right) .
$$

In equation (8) the influence of the flow shallowness and the sediment coarseness is not negligible in principle, contrary to the hypothesis we have used to derive expressions (2), (4) and (5).

\section{Experimental Setup and Procedure}

The experiments were carried out in a $3.0 \mathrm{~m}$ wide and $7.0 \mathrm{~m}$ long rectangular concrete flume, located at the Hydraulics Laboratory of the Universidad Castilla-La Mancha, Spain. The flume has a working section in the form of a $4.0 \mathrm{~m}$ long recess in the bottom that was filled with sand to a uniform thickness of $0.60 \mathrm{~m}$. At the entrance of the flume, arrangements were made to guarantee a uniform transverse flow distribution; the upstream concrete bed was covered with gravel to promote the flow boundary layer development. At the downstream end, a tailgate allowed the regulation of the water depth. The sand used to fill the bed recess, similar to that used by Lanca et al. (2013), was characterized by $\rho_{s}=2650 \mathrm{~kg} / \mathrm{m}^{3}$, $D_{50}=0.90 \mathrm{~mm}$ and $\sigma_{D}=1.30$.

All the tests were carried out with a constant approach flow depth, $d=0.20 \mathrm{~m}$, and average velocity, $U=0.31 \mathrm{~m} / \mathrm{s} \approx U_{c}=0.33 \mathrm{~m} / \mathrm{s} ;$ this value of $U_{c}$ was computed through the expression by Neil (1967). The discharge in the flume was measured with a calibrated V-notch weir and was kept equal to $0.124 \mathrm{~m}^{3} / \mathrm{s}$, and an ADV was used to measure the velocity profile upstream the pile group and to ensure that the boundary layer was properly developed near the pile group. Figure 3 shows the measured velocity profile together with the fitted logarithmic velocity law (gray line in the figure) for the mean values. The good agreement with the logarithmic profile indicates the full development of the boundary layer; further, the depth averaged value of the logarithmic profile was $0.31 \mathrm{~m} / \mathrm{s}$.

Forty-eight tests were performed: all combinations for $S_{r} \in\{0,1 / 6,1 / 3,1 / 2,2 / 3,5 / 6\}, \alpha \in$ $\left\{0^{\circ}, 15^{\circ}, 30^{\circ}, 45^{\circ}\right\}$ and $n \in\{1,2\}$. In all cases $m=4$, as mentioned, and the diameter of the PVC piles was $D_{p}=50 \mathrm{~mm}$, constant, so that the sand coarseness factor was $D_{p} / D_{50}=56$, below 100 as mentioned. Note that the tests where $S_{r}=0$ correspond to an emergent pile group (i.e., $\left.d_{S g e}\left(S_{r}=0\right)=d_{E g e}\right)$. The equilibrium depth scour for the tests with $S_{r}=\alpha=0$ (two tests, one for $n=1$ and one for $n=2$ ) are denoted as $d_{E g e 0}$, and are used as a reference value.

The pile groups were placed at the center of the bed recess box, approximately $4.0 \mathrm{~m}$ downstream the flume inlet and, prior to each test, the sand of the recess box was levelled with the adjacent bed. The area located around the piles was then covered with thin perforated metallic plates and the flume was 


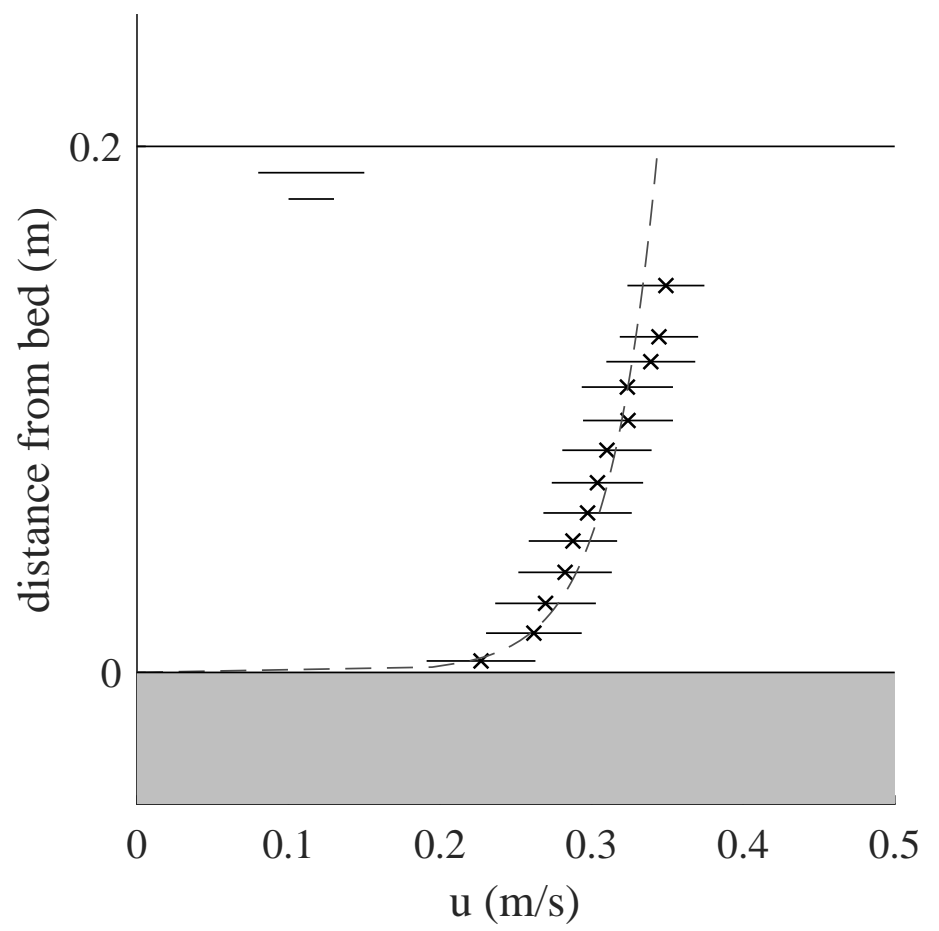

Figure 3. Measurements of approach velocity measures using an ADV $1 \mathrm{~m}$ upstream pile group. Dashed grey line represents an adjusted logarithmic velocity profile $\left(U_{\text {adjusted }}=0.311 \mathrm{~m}\right)$.

filled at a low rate. Once the flume was filled, the discharge rate was set and the flow depth was slowly reduced using the tailgate to reach the desired flow depth (and velocity), and the metallic plates were carefully removed with the help of a bridge crane to start the test.

The scour process initiated and the depth of the scour hole was measured just upstream of each pile with an accuracy of $\pm 0.1 \mathrm{~mm}$, using one adapted point gauge, at high frequency (up to six measurements per hour) during the first day. After the first day, three or four measurements were made each day. Each of the experiments was run, at least, until Melville's equilibrium condition was satisfied (Melville and Chiew, 1999), i.e., until the increment of the scour at the pile of maximum scour was smaller than $0.05 D_{p}$ in 24 hours. According to Simarro et al. (2011), the duration of the experiments, in order to allow a proper estimation of the equilibrium scour, is in the order of few weeks. Further, they showed that the criteria by Melville and Chiew (1999) can lead, for the isolated emergent pile case, to significant errors in the estimation of the equilibrium scour depth.

The average duration of the experiments was 9.1 days (from 5.9 days up to 21.0 days), which enabled an estimate of the equilibrium scour depth to be made according to Simarro et al. (2011). These durations are much longer than the vast majority of those reported in the literature, and they exceed in all tests except for one $\left(S_{r}=0, \alpha=45^{\circ}, n=1\right)$, the time introduced by Sheppard and Melville (2011) which has also been considered as a good approach for the test duration according to Moreno et al. (2016). The sand bed upstream the pile group (and scour hole) remained undisturbed throughout the entire duration of the tests. 


\begin{tabular}{|c|c|c|c|c|c|c|c|c|c|c|c|c|c|}
\hline \multirow{2}{*}{$\begin{array}{l}\alpha \\
\left({ }^{\circ}\right)\end{array}$} & \multirow[b]{2}{*}{$S_{r}$} & \multicolumn{6}{|c|}{$n=1\left(n D_{p}=0.05 \mathrm{~m}\right)$} & \multicolumn{6}{|c|}{$n=2\left(n D_{p}=0.10 \mathrm{~m}\right)$} \\
\hline & & test & $\begin{array}{c}t_{d} \\
\text { (days) }\end{array}$ & $\begin{array}{c}d_{S g \max } \\
(\mathrm{m})\end{array}$ & $\begin{array}{c}d_{S g e} \\
(\mathrm{~m})\end{array}$ & $\begin{array}{l}B_{g} \\
(\mathrm{~m})\end{array}$ & $\begin{array}{l}D_{e} \\
(\mathrm{~m})\end{array}$ & test & $\begin{array}{c}t_{d} \\
\text { (days) }\end{array}$ & $\begin{array}{c}d_{S g \max } \\
(\mathrm{m})\end{array}$ & $\begin{array}{c}d_{S g e} \\
(\mathrm{~m})\end{array}$ & $\begin{array}{l}B_{g} \\
(\mathrm{~m})\end{array}$ & $\begin{array}{l}D_{e} \\
(\mathrm{~m})\end{array}$ \\
\hline \multirow{6}{*}{0} & 0 & 1 & 7.8 & 0.138 & 0.142 & \multirow{6}{*}{0.050} & 0.050 & 25 & 9.0 & 0.137 & 0.141 & \multirow{6}{*}{0.100} & 0.100 \\
\hline & $1 / 6$ & 2 & 6.0 & 0.125 & 0.127 & & 0.042 & 26 & 8.9 & 0.101 & 0.112 & & 0.083 \\
\hline & $2 / 6$ & 3 & 7.0 & 0.121 & 0.126 & & 0.033 & 27 & 7.0 & 0.134 & 0.140 & & 0.067 \\
\hline & $3 / 6$ & 4 & 6.0 & 0.117 & 0.125 & & 0.025 & 28 & 7.9 & 0.139 & 0.144 & & 0.050 \\
\hline & $4 / 6$ & 5 & 7.0 & 0.114 & 0.124 & & 0.017 & 29 & 5.9 & 0.139 & 0.139 & & 0.033 \\
\hline & $5 / 6$ & 6 & 6.0 & 0.100 & 0.107 & & 0.008 & 30 & 7.9 & 0.130 & 0.135 & & 0.017 \\
\hline \multirow{6}{*}{15} & 0 & 7 & 9.0 & 0.139 & 0.144 & \multirow{6}{*}{0.147} & 0.147 & 31 & 10.1 & 0.155 & 0.171 & \multirow{6}{*}{0.229} & 0.229 \\
\hline & $1 / 6$ & 8 & 8.9 & 0.126 & 0.134 & & 0.123 & 32 & 9.0 & 0.160 & 0.177 & & 0.191 \\
\hline & $2 / 6$ & 9 & 8.9 & 0.120 & 0.121 & & 0.098 & 33 & 7.9 & 0.168 & 0.176 & & 0.153 \\
\hline & $3 / 6$ & 10 & 8.0 & 0.111 & 0.113 & & 0.074 & 34 & 8.5 & 0.136 & 0.142 & & 0.115 \\
\hline & $4 / 6$ & 11 & 10.0 & 0.093 & 0.094 & & 0.049 & 35 & 7.9 & 0.132 & 0.141 & & 0.077 \\
\hline & $5 / 6$ & 12 & 10.3 & 0.074 & 0.080 & & 0.025 & 36 & 7.9 & 0.101 & 0.111 & & 0.038 \\
\hline \multirow{6}{*}{30} & 0 & 13 & 8.0 & 0.153 & 0.155 & \multirow{6}{*}{0.200} & 0.200 & 37 & 10.1 & 0.172 & 0.185 & \multirow{6}{*}{0.296} & 0.296 \\
\hline & $1 / 6$ & 14 & 9.1 & 0.122 & 0.129 & & 0.167 & 38 & 9.0 & 0.170 & 0.179 & & 0.247 \\
\hline & $2 / 6$ & 15 & 7.9 & 0.132 & 0.136 & & 0.133 & 39 & 9.0 & 0.151 & 0.161 & & 0.197 \\
\hline & $3 / 6$ & 16 & 9.9 & 0.111 & 0.113 & & 0.100 & 40 & 7.9 & 0.136 & 0.139 & & 0.148 \\
\hline & $4 / 6$ & 17 & 10.0 & 0.109 & 0.112 & & 0.067 & 41 & 13.9 & 0.133 & 0.139 & & 0.099 \\
\hline & $5 / 6$ & 18 & 8.9 & 0.105 & 0.115 & & 0.033 & 42 & 13.0 & 0.119 & 0.127 & & 0.049 \\
\hline \multirow{6}{*}{45} & 0 & 19 & 6.9 & 0.147 & 0.156 & \multirow{6}{*}{0.200} & 0.200 & 43 & 12.0 & 0.190 & 0.193 & \multirow{6}{*}{0.250} & 0.250 \\
\hline & $1 / 6$ & 20 & 12.9 & 0.151 & 0.162 & & 0.167 & 44 & 14.9 & 0.173 & 0.187 & & 0.208 \\
\hline & $2 / 5$ & 21 & 8.9 & 0.130 & 0.136 & & 0.133 & 45 & 9.9 & 0.162 & 0.167 & & 0.167 \\
\hline & $3 / 5$ & 22 & 9.1 & 0.101 & 0.106 & & 0.100 & 46 & 21.0 & 0.158 & 0.159 & & 0.125 \\
\hline & $4 / 6$ & 23 & 8.0 & 0.088 & 0.095 & & 0.067 & 47 & 7.9 & 0.146 & 0.154 & & 0.083 \\
\hline & $5 / 6$ & 24 & 10.1 & 0.112 & 0.115 & & 0.033 & 48 & 7.9 & 0.148 & 0.158 & & 0.042 \\
\hline
\end{tabular}

Table 1. Control variables and scour for the tests.

\section{Results}

A summary of the main variables and results for the 48 tests is presented in Table 1 . Note that the time appearing in Table 1 is the duration of the experiment which is, in any case, greater than the equilibrium time defined by Melville's condition.

This table includes the test durations and the scour depth observed at the pile with the maximum scour depth at the end of the experiment, given as $d_{S g \max }$. The corresponding piles are identified as full circles in Fig. 4 .

From Fig. 4, for $n=1$ and small values of $\alpha$, e.g., $\alpha=\left\{15^{\circ}, 30^{\circ}\right\}$, it can be concluded that the maximum scour appeared mostly at the most exposed pile (i.e., pile 1). For larger values of $\alpha$, and 


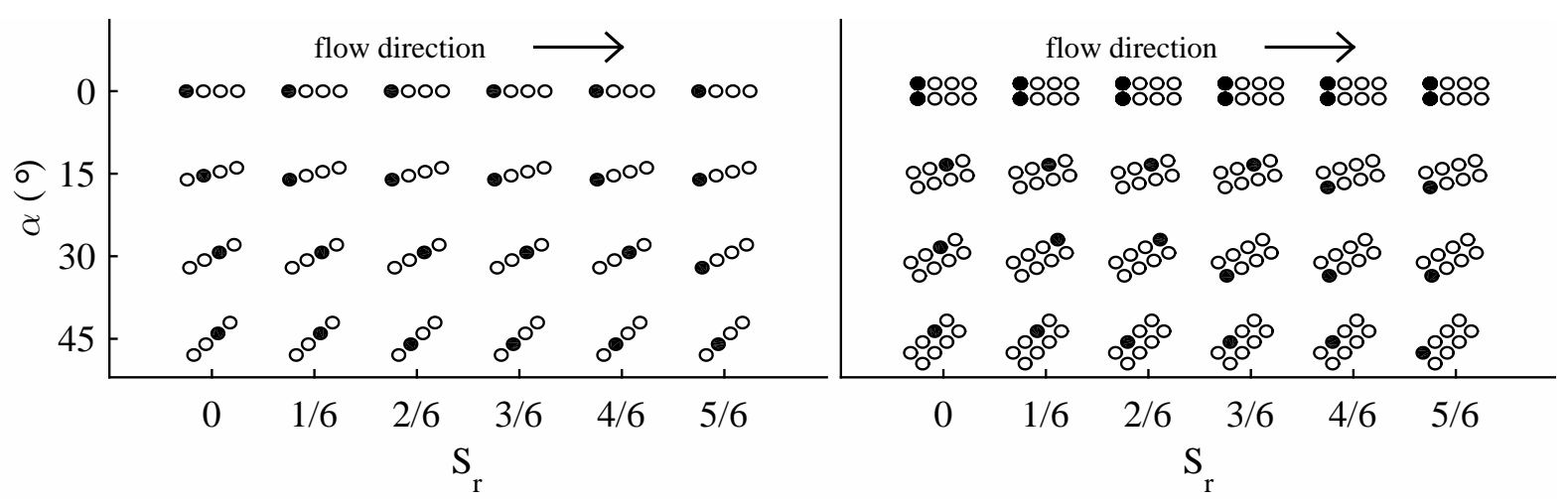

Figure 4. Location of maximum scour. The pile in which the maximum value of scour depth occurs is represented in black. Not to scale.

$n=1$, the location of the maximum scour moved to the back of the pile group, appearing at piles 2 and 3 for small values of $S_{r}$, although it remained mainly at the front of the pile group for large values of $S_{r}$.

For $n=2$, the behaviour was more complex, due to the interaction between the vortices generated by the two columns. For $\alpha=0^{\circ}$, the maximum scour depth was observed at the most exposed piles (1 and 5). Besides, for $\alpha=45^{\circ}$, the behaviour was similar to that for $n=1$. Only when $\alpha=15^{\circ}$ and $S_{r} \geqslant$ $4 / 6$ or $\alpha=30^{\circ}$ and $S_{r} \geqslant 3 / 6$ did the location of the maximum scour depth move to the second column of the piles (pile 5). These results were in good agreement with the literature (Hannah, 1978; Hosseini and Amini, 2015; Lanca et al., 2013; Zhao and Sheppard, 1998). The main scour mechanisms at pile groups, as described by Hannah (1978), are reinforcing, sheltering, shed vortices and the compressed horseshoe vortex. Hosseini and Amini (2015) studied the strength of these mechanisms depending on the skew-angle and distance between piles, and Zhao and Sheppard (1998) found that for skewed piles, when $\alpha<20^{\circ}$, the maximum scour depth occurs near the front of the pile group (i.e., piles 1 or 5 in this study), while, for $\alpha>20^{\circ}$, the maximum scour occurs at the first column (piles from 1 to 4 ). For $\alpha \approx 25^{\circ}$ the position of the maximum scour depth is due to the vortices generated by the most exposed piles impinging directly on the downstream piles. This distribution of vortices paths could explain the movement downstream of the location of the maximum scour for skewed piles.

Table 1 also includes $d_{S g e}$, the equilibrium scour obtained by extrapolating to infinite time the measured scour depths following the procedure suggested by Lanca et al. (2013) for the pile where the scour was maximal at the end of the test. The results for $d_{S g e}$ are, in general, slightly larger that $d_{S g \max }$, with $d_{S g e} / d_{S g \max }=1.050 \pm 0.029$.

The time evolution of the scour depth at the piles where scour was maximal are shown in Fig. 5 for all tests. The complete time evolution of the scour depths are available at https://www.dropbox. $\mathrm{com} / \mathrm{s} / 0 \mathrm{hmi}$ et $7 \mathrm{t} \times 8 \mathrm{~d} 1 \mathrm{xr} / \mathrm{Data} \cdot \mathrm{rar} ? \mathrm{dl}=0$.

Figure 5 also includes, for comparison purposes, the values $d_{E g e 0}=d_{S g e}\left(S_{r}=\alpha=0\right)$ for $n=1$ and $n=2$ : as shown in Table 1 , the values are $0.141 \mathrm{~m}$ and $0.142 \mathrm{~m}$ respectively, indistinguishable in 


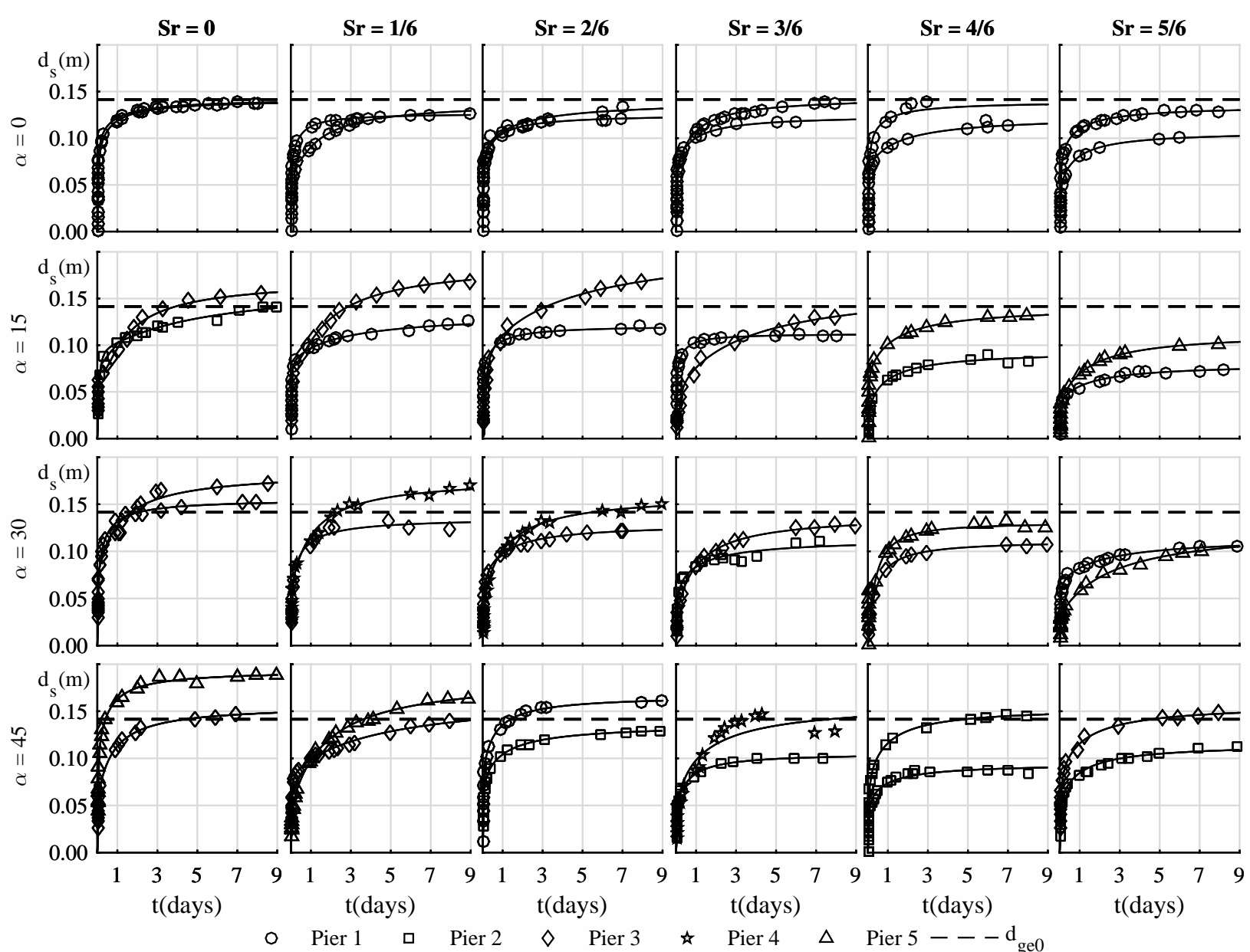

Figure 5. Scour depth time evolution at pile groups for $n=1$ (grey) and $n=2$ (black). Discontinuous line represents $d_{E g e 0}$ (indistinguishable values for $n=1$ and $n=2$ encountered).

the figure. From Fig. 5, for $n=1$ (grey), the equilibrium scour is smaller than $d_{S g e 0}$ for most of the tests. In other words, the joint effect of the skew-angle and submergence rarely makes the scour increase relative to the aligned and emergent cases. Moreover, the maximum value of $d_{S g e}$ is $\sim 1.15 d_{E g e 0}$ so that $d_{E g e 0}$ could roughly be considered as an upper limit of the scour for any skew-angle and submergence ratio in the range of this study. For $n=2$, though, $d_{E g e 0}$ is surpassed in a wider variety of cases, and $d_{S g e} / d_{E g e 0}$ reaches values of up to 1.37 .

Following the dimensional arguments in the previous section, Fig. 6 shows $d_{S g e}$ normalized with different characteristic lengths $\left(n D_{p}, B_{g}\right.$ and $\left.D_{e}\right)$, as a function of $S_{r}$ and $\alpha$ both for $n=1$ and $n=2$. Using $n D_{p}$ to normalize the scour depth, Fig. 6 shows that the influences of both $S_{r}$ and $\alpha$ are small, although there is a general trend for $d_{S g e} /\left(n D_{p}\right)$ to decrease as $S_{r}$ increases. The purpose of using $B_{g}$ to normalize, as compared to $n D_{p}$, is to include the effect of the skew-angle $\alpha$. However, as shown in Fig. 6. using $B_{g}$ does not properly show the influence of $\alpha$ : on the contrary, the figure shows that $d_{S g e} / B_{g}$ is greatly influenced by $\alpha$. This is consistent with the fact that the influence of $\alpha$ on $d_{S g e} /\left(n D_{p}\right)$ is small. Note that, since neither $n D_{p}$ nor $B_{g}$ include the submergence, the behaviour of $d_{S g e} /\left(n D_{p}\right)$ and $d_{S g e} / B_{g}$ relative to $S_{r}$ is similar. Using $D_{e}$ to scale the scour depth, the influence of $\alpha$ is the same as 
that observed for $B_{g}$ but, further, the influence of $S_{r}$ seems not to be properly demonstrated.

Figure 6 includes the experimental results by Amini et al. (2012) for $\alpha=0^{\circ}, S / D_{p}=2$ and $n=2$, i.e. only tests with the closest value of $S / D_{p}$ to those in the present study: their results are significantly smaller that ours. Of note, they present results for the scour measured (or extrapolated) at 24 hours, while our experiments are meant to obtain equilibrium scour depths. For the experiments with $n=2$ in the present study, the scour depths after 24 hours of experiment were $65 \% \pm 21 \%$ of the equilibrium depths.

The fact that $n D_{p}$ is the length that makes the normalized scour to be more uniform suggests the use of an expression as simple as

$$
d_{\text {Sge }}=C_{n} n D_{p},
$$

for $n \in\{1,2\}$ and with constants $C_{1}$ and $C_{2}$. In doing so, for $n=1, C_{1}=2.47$ (RME $=0.020 \mathrm{~m}$ ) and, for $n=2, C_{2}=1.55(\mathrm{RME}=0.021 \mathrm{~m})$.

Trying to introduce the effect of submergence observed above, a slightly more sophisticated variation is

$$
d_{S g e}=C_{n} n D_{p}\left(1-S_{r}\right)^{\beta_{n}},
$$

so that now, for $n=1, C_{1}=2.87, \beta_{1}=0.23(\mathrm{RME}=0.012 \mathrm{~m})$ and, for $n=2, C_{2}=1.72, \beta_{1}=0.16$ $(\mathrm{RME}=0.014 \mathrm{~m})$.

Figure 7 shows the comparison of the experimental value of $d_{S g e}$ and the values of the expressions (9) and (10). Using the expression (9), that does not introduce the submergence ratio, the computed values of $d_{S g e}$ lead to relative errors up to $54.4 \%$ (Fig. 7. (a)). In addition, Equation (10), which introduces the influence of $S_{r}$ previously noted, reduces the errors below $22.0 \%$ (Fig. 7. (b)), and the adjustment to the experimental data is good despite the expression not including the skew-angle.

In previous sections we have mentioned some of the methods most used for the prediction of $d_{S g e}$ (Amini et al., 2012, Richardson and Davis, 2001; Sheppard and Renna, 2010). On the one hand, the proposed expression (10) is formally similar to the predictor by Amini et al. (2012), given by Equation (6), since both methods retain the influence of submergence but neglecting the influence of skew-angle. However, the characteristic length used to normalize the equilibrium scour depth $\left(n D_{p}\right.$ and $d_{n D_{p}}$, respectively) and the test durations are different. In fact, the expression by Amini et al. (2012) provides values consistently smaller than the experimental results shown in Fig. 6. On the other hand, only one of the two methods for complex piers (including pile-cap and pier-stem), HEC-18 method by Richardson and Davis (2001), is applicable to the tests performed here. FDOT by Sheppard and Renna (2010) does not meet the hypothesis of the present work as mentioned above.

HEC-18 for complex piers estimates the total scour depth as the superposition of scour due to each 

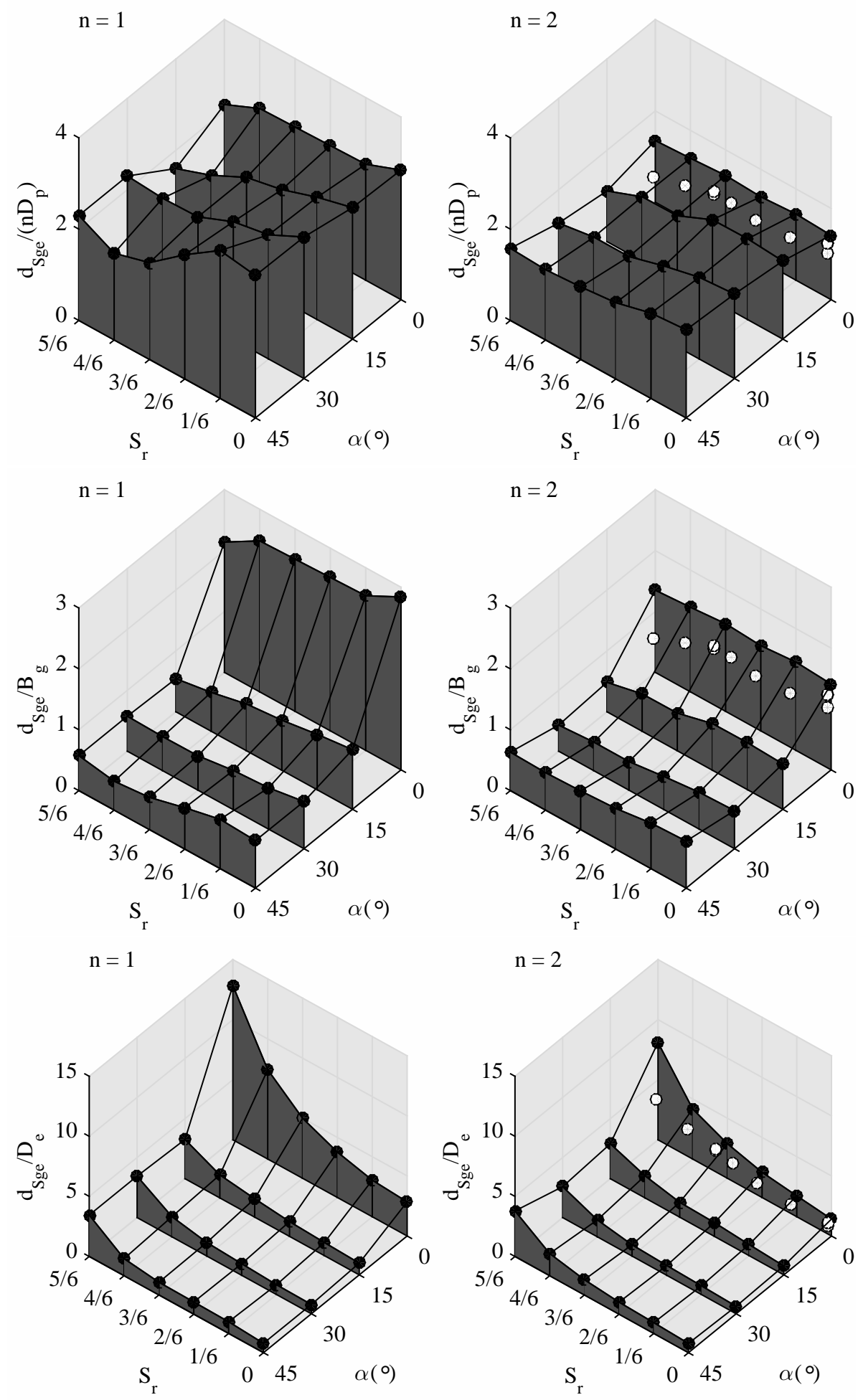

Figure 6. Equilibrium scour depth at pile group, $d_{S g e}$, normalized with $n D_{p}, B_{g}$ and $D_{e}$. Experiments by Amini et al. (2012) are denoted with white circles. 

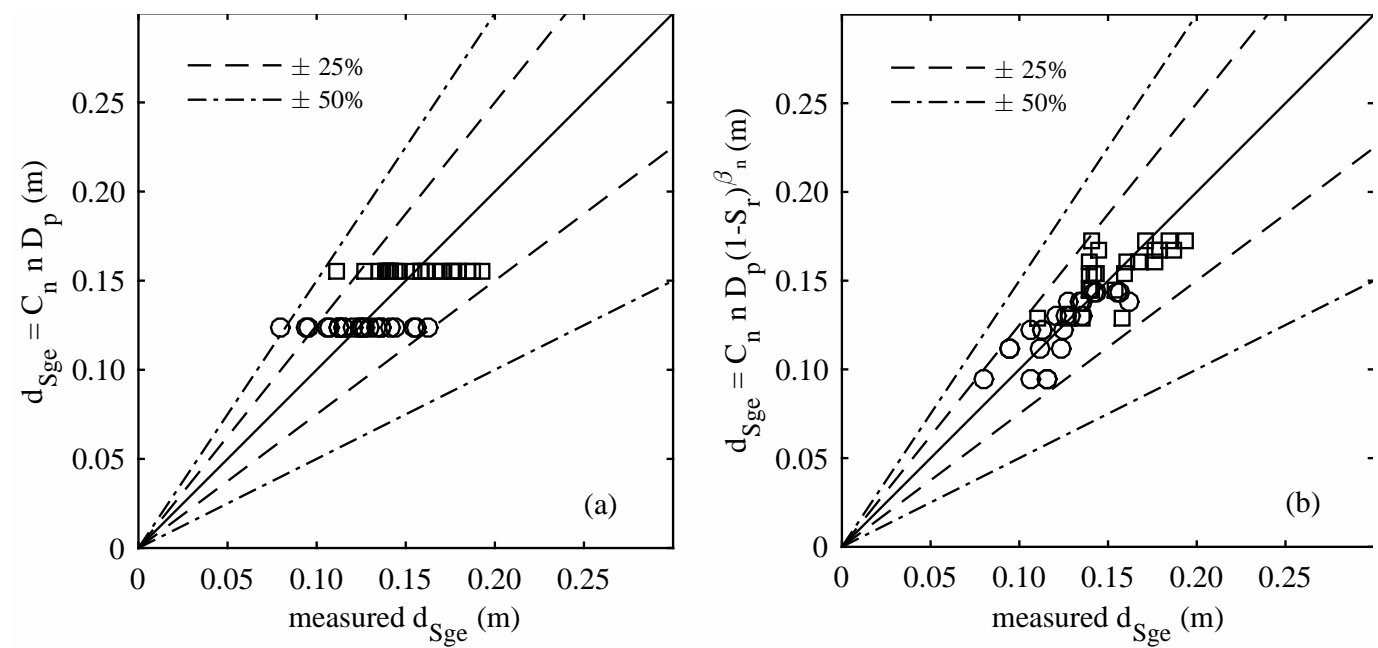

Figure 7. Comparison of experimental and computed equilibrium scour depths at pile group using the new proposed expressions. Circles represents tests with $n=1$ and squares tests with $n=2$.

individual component (pile group, pile-cap and pier-stem). For this study, only the contribution of pile group is considered through Equation (7). Figure 8 (a) represents the comparison between experimental value of $d_{S g e}$ and HEC-18. As shown, HEC-18 tends to underestimate the equilibrium scour depth both for $n=1$ and $n=2$. For larger values of submergence, i.e., $S_{r} \geqslant 0.5$, the errors reach values of up to $76.3 \%$, and the errors decrease as the submergence $S_{r}$ decreases (this fact cannot be corroborated by Fig. 8). This seems to indicate that the original function

$$
K_{h}\left(S_{r}\right)=\left[3.08(1-S r)-5.23(1-S r)^{2}+5.25(1-S r)^{3}-2.1(1-S r)^{4}\right]^{\frac{1}{0.65}}
$$

employed by HEC-18 does not properly capture the influence of $S_{r}$ when pier-stem and pile-cap are not explicitly considered. Based on the experimental values presented here, a new and simpler expression for $K_{h}$ is proposed. Since Equation (7) uses $B_{g}$ to compute $d_{S g e}$, the behaviour of the experimental values of $K_{h}$ when $\alpha=0$ is quite different from the cases with $\alpha \neq 0$, as it shown in Fig. 6 when $B_{g}$ or $D_{e}$ are considered as normalizing length. The proposed expression for $K_{h}$ reads

$$
K_{h}(S r)=\delta-\gamma S_{r}
$$

where coefficients $\delta$ and $\gamma$, which depend only on $\alpha$, are obtained to mimic the differences, in terms of the root mean square error, between the predicted values of $d_{S g e}$ and the observed ones. Note that the number of coefficients has been reduced from five in the original expression for $K_{h}$ to four in the proposed one.

The derived values for $\delta$ and $\gamma$ are shown in Table 2 and the computed scour is shown in Fig. 8 (b). As shown, the computed values are closer to the experimental values than those using the original 
Table 2. Coefficients for the new proposed

\begin{tabular}{lll}
\hline \hline & $\alpha=0^{\circ}$ & $\alpha \geq 15^{\circ}$ \\
\hline$\delta$ & 1.17 & 1.00 \\
$\gamma$ & 0.18 & 0.40 \\
\hline \hline
\end{tabular}
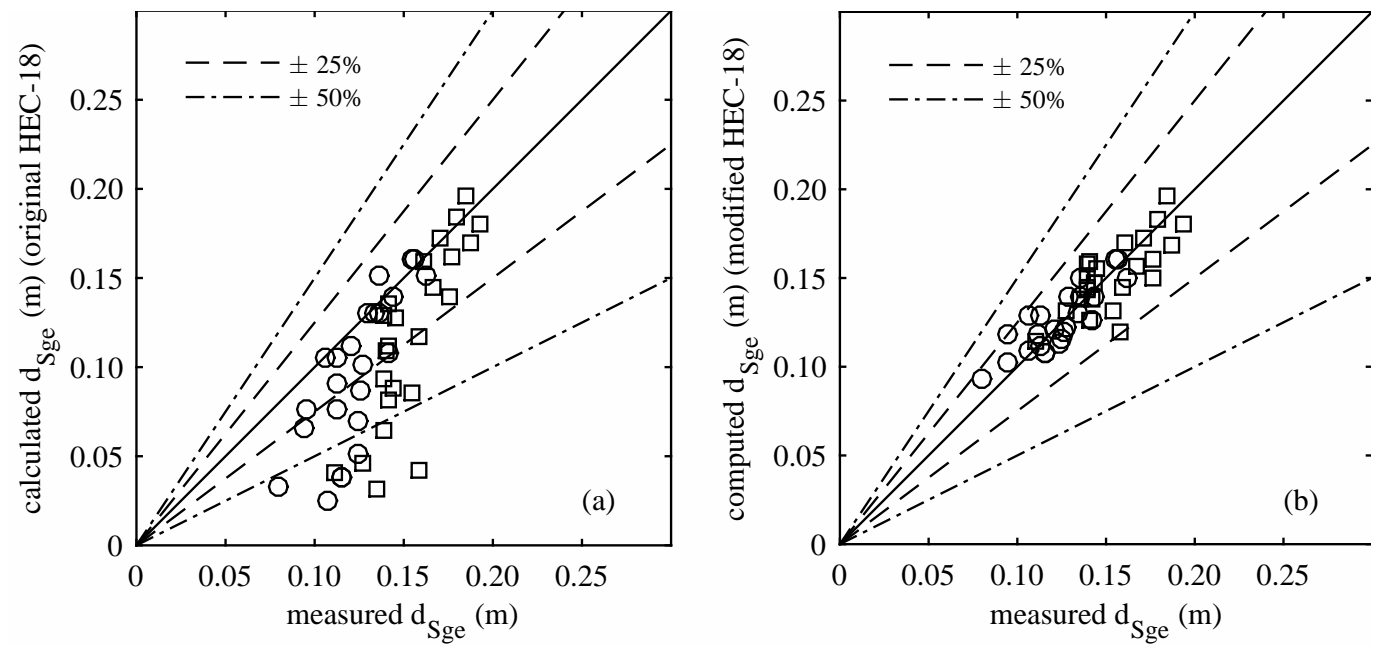

Figure 8. Comparison of experimental and computed equilibrium scour depth at pile group using original HEC-18 method (a) and proposed modification of HEC-18 method (b). Circles represents tests with $n=1$ and squares tests with $n=2$.

expression from HEC-18. The maximum error reduces from $76.3 \%$ to $24.2 \%$.

\section{Conclusions}

In this study, 48 long-duration experiments were performed to find the influence of the submergence, $S_{r}$, and the skew-angle, $\alpha$, on the equilibrium scour depth at submerged pile groups, $d_{S g e}$, under two different arrangements ( 4 rows $\times 1$ column and 4 rows $\times 2$ columns) within the range where shallowness effects on scour depth can be neglected $\left(d / D_{p} \gtrsim 2.5\right)$. The experimental results were compared with those of the HEC-18 empirical method (Richardson and Davis, 2001). Since this formulation determines the total scour depth for a complex pier (pile group, pile-cap and pier-stem) by separating the scour producing components, determining the scour depth for each component and adding the results, a new correction factor was proposed for the case where only the submerged pile group remains. Using this modification, the differences between experimental and empirical values decreased from $76 \%$ to $24 \%$. Additionally, a new expression was derived based on the fact that the greater the submergence the smaller the equilibrium scour at the pile group and no significant variations exist with the skew-angle. In this case, the computed differences are about $22 \%$. In the past, a range of different characteristic lengths have been used to normalize the equilibrium scour depth to absorb the influence of $S_{r}$ and $\alpha$, with $B_{g}$ and $D_{e}$ standing out. However, in this study it is seen that the characteristic length producing the best fit with observations is $n D_{p}$, which does not consider either $S_{r}$ or $\alpha$. 


\section{Acknowledgements}

The authors would like to thank Eduardo Díaz for his help in preparing the experiments and Dr. Roger Bettess for his English review of the last version of the text.

\section{References}

Amini, A., et al., 2012. Clear-water local scour around pile groups in shallow-water flow. Journal of Hydraulic Engineering-Asce, 138 (2), 177-185.

Amini, A., Melville, B.W., and Thamer, M.A., 2014. Local scour at piled bridge piers including an examination of the superposition method. Canadian Journal of Civil Engineering, 41 (5), 461-471.

Amini, A. and Thamer, M.A., 2016. Local scour prediction around piers with complex geometry. Marine Georesources \& Geotechnology, $0(0), 1-8$.

Amini, A., et al., 2011. A local scour prediction method for pile caps in complex piers. Proceedings of the Institution of Civil Engineers - Water Management, 164 (2), 73-80.

Azamathulla, H.M., et al., 2013. Genetic programming to predict bridge pier scour (vol 136, pg 165, 2010). Journal of Hydraulic Engineering, 139 (9), 1020-1020.

Ballio, F., Teruzzi, A., and Radice, A., 2009. Constriction effects in clear-water scour at abutments. Journal of Hydraulic Engineering-Asce, 135 (2), 140-145.

Bauri, K.P. and Sarkar, A., 2016. Flow and scour around vertical submerged structures. SadhanaAcademy Proceedings in Engineering Sciences, 41 (9), 1039-1053.

Breusers, H.N.C., Nicollet, G., and Shen, H.W., 1977. Local scour around cylindrical piers. Journal of Hydraulic Research, 15 (3), 211-252.

Chreties, C., Teixeira, L., and Simarro, G., 2013. Influence of flow conditions on scour hole shape for pier groups. Proceedings of the Institution of Civil Engineers-Water Management, 166 (3), 111-119.

Coleman, S.E., 2005. Clearwater local scour at complex piers. Journal of Hydraulic Engineering-Asce, 131 (4), 330-334.

Dey, S., Raikar, R.V., and Roy, A., 2008. Scour at submerged cylindrical obstacles under steady flow. Journal of Hydraulic Engineering-Asce, 134 (1), 105-109.

Euler, T. and Herget, J., 2011. Obstacle-reynolds-number based analysis of local scour at submerged cylinders. Journal of Hydraulic Research, 49 (2), 267-271.

Hannah, C.R., 1978. Scour at pile groups. Thesis (Masters). University of Canterbury, Christchurch, New Zealand.

Hosseini, R. and Amini, A., 2015. Scour depth estimation methods around pile groups. KSCE Journal of Civil Engineering, 19 (7), 2144-2156.

Lanca, R., et al., 2013. Clear-water scour at pile groups. Journal of Hydraulic Engineering, 139 (10), 
1089-1098.

Melville, B.W., 1997. Pier and abutment scour: Integrated approach. Journal of Hydraulic EngineeringAsce, 123 (2), 125-136.

Melville, B.W. and Chiew, Y.M., 1999. Time scale for local scour at bridge piers. Journal of Hydraulic Engineering-Asce, 125 (1), 59-65.

Moreno, M., Maia, R., and Couto, L., 2016. Effects of relative column width and pile-cap elevation on local scour depth around complex piers. Journal of Hydraulic Engineering, 142 (2), 9.

Neil, C.R., 1967. Mean velocity criterion for scour of coarse uniform bed-material. In: Proceedings of the 12th IAHR Congress.

Razmi, M.M., Sanei, M., and Ershadi, C., 2014. The effect of submergence percentage of the submerged piles on the reduction of scour in bridge abutments. Journal of Rehabilitation in Civil Engineering, 32-39.

Richardson, E.V. and Davis, S.R., 2001. Evaluating scour at bridges. Federal Highway Administration.

Salim, M. and Jones, J.S., 1996. Scour around exposed pile foundations. In: Proceedings North American Water ans Environment Conference '96.

Sarkar, A. and Ratha, D., 2014. Flow around submerged structures subjected to shallow submergence over plane bed. Journal of Fluids and Structures, 44, 166-181.

Shamloo, H., Rajaratnam, N., and Katopodis, C., 2001. Hydraulics of simple habitat structures. Journal of Hydraulic Research, 39 (4), 351-366.

Sheppard, D.M. and Glasser, T., 2004. Sediment scour at piers with complex geometries. In: Proceedings. 2004, 2nd International Conference on Scour and Erosion.

Sheppard, D.M. and Renna, R., 2010. Bridge scour manual. Florida Department of Transportation.

Sheppard, D. M., D.H. and Melville, B., 2011. Scour at wide piers and long skewed piers. Florida Department of Transportation.

Simarro, G., Fael, C.M.S., and Cardoso, A.H., 2011. Estimating equilibrium scour depth at cylindrical piers in experimental studies. Journal of Hydraulic Engineering-Asce, 137 (9), 1089-1093.

Zhao, M., Cheng, L.A., and Zang, Z.P., 2010. Experimental and numerical investigation of local scour around a submerged vertical circular cylinder in steady currents. Coastal Engineering, 57 (8), 709721.

Zhao, M. and Sheppard, D.M., 1998. The effect of flow skew-angle on sediment scour near pile groups. In: Stream Stability and Scour at Highway Bridges, compendium of papers ASCE Water Resource Engineering conferences 1991-1998. 377-391. 